\title{
Coeliac trunk and its anatomic variations: a cadaveric study
}

\author{
A. Juszczak@ (D. Mazurek, J.A. Walocha, A. Pasternak \\ Department of Anatomy, Jagiellonian University Medical College, Krakow, Poland \\ [Received: 1 February 2020; Accepted: 30 March 2020]
}

Background: Coeliac trunk (CT) is the first major visceral branch of the abdominal aorta. The aim of this work was to present the CT division pattern and its anatomical variants in a sample of Polish population.

Materials and methods: Coeliac trunk dissection was performed in 50 adult cadavers in the Department of Anatomy, Jagiellonian University Medical College. Cadavers of Polish subjects were included. Cadavers with previous upper abdominal surgery, abdominal trauma, disease process that distorted arterial anatomy or signs of putrefaction were excluded. CT variations, accessory vessels, and vertebral level of origin were described. CT patterns were reported according to the Adachi classification. This study was reviewed and approved by the local Ethics Committee. Results: Coeliac trunk consisting of the left gastric, common hepatic and splenic artery (type 1 according to the Adachi classification) was found in 82\% of cadavers. The true tripod was found in $20 \%$ and the false one in $80 \%$. Additional vessels were also found: greater pancreatic from the splenic artery and left inferior phrenic from the left gastric artery, which accounted for $2 \%$ sections. Type 2 according to the Adachi classification (i.e. the hepatosplenic trunk) was found in $16 \%$ of the sections. Other types of CT were not observed. The level of origin was found to be at the inter-vertebral disc between T12 and L1 in all of the cases.

Conclusions: Based on the analysis of the sectional material of the Department of Anatomy, it was found that the typical visceral segmental division is approximate to that observed by Adachi in its classification, whereas the second type of CT was twice as frequent and no other, less frequent types were found. (Folia Morphol 2021; 80, 1: 114-121)

Key words: tripod, anatomical variations, Adachi classification, coeliac trunk

\section{INTRODUCTION}

The coeliac trunk (CT) is the first anterior visceral branch of the abdominal aorta (AA) and it arises from AA immediately below the aortic hiatus at the level of T12-L1 vertebra. It measures $1.5-2 \mathrm{~cm}$. It runs down, right and slightly forward, lying back from the lesser omentum. Its ending lies just above the upper border of the pancreas. CT is surrounded by the coeliac plexus. It was first described by Albrecht von Haller in 1756 [13], as "tripus Halleri", which represents the classical type of branching, known as trifurcation in the left gastric artery (LGA), common hepatic artery (CHA) and splenic artery (SA). Anatomic variation of CT has been first classified by Adachi in 1928 [1], based on 252 dissections of Japanese cadavers, where six types of divisions were described (Fig. 1). However, two forms of trifurcation have been most commonly observed: a "true" tripod is considered when the 


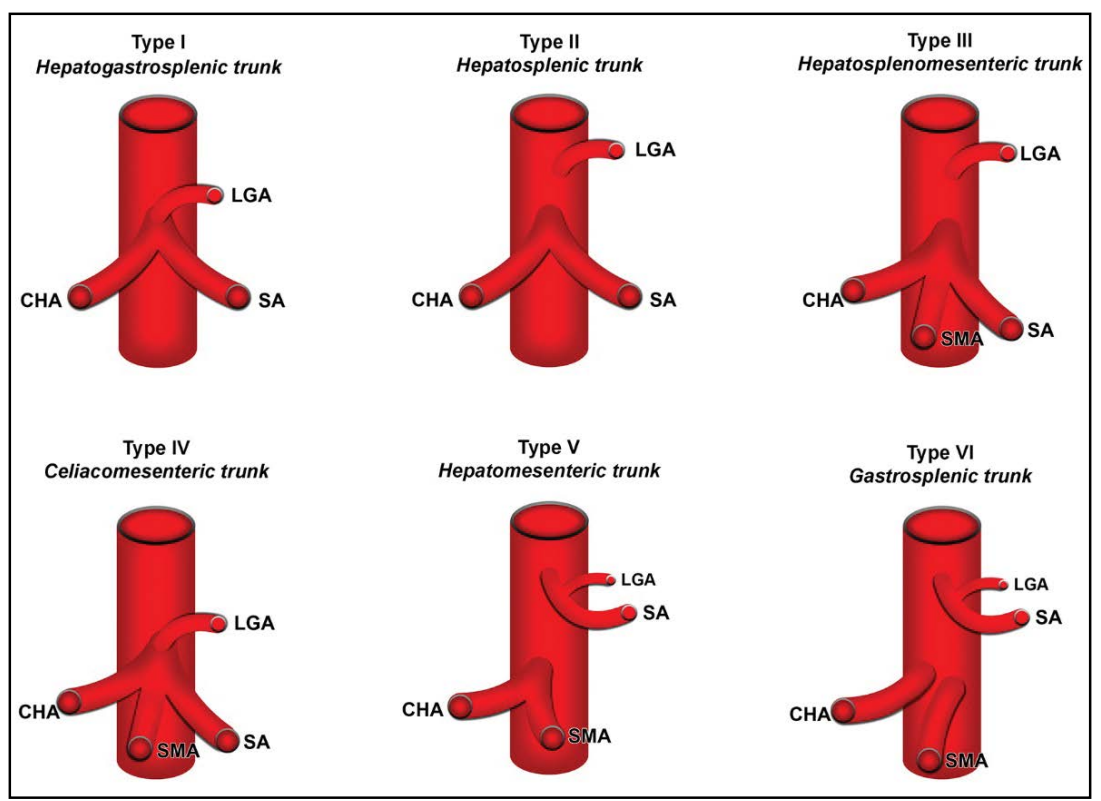

Figure 1. Coeliac trunk variations according to Adachi; CHA — common hepatic artery; LGA — left gastric artery; SA — splenic artery; SMA - superior mesenteric artery.

CHA, LGA and SA have a common origin, constituting a hepatogastrosplenic trunk. When one of these arteries arises before the remaining two in the course of the $\mathrm{CT}$, it is called a false tripod [36]. CT supplies the structures derived from the foregut (liver, pancreas, abdominal part of the oesophagus, stomach and proximal duodenum). Surgery of the abdominal cavity requires an excellent knowledge of anatomical variations of the CT. Familiarity with the vascular supply of abdominal organs such as liver or pancreas is basic for numerous procedures (chemo-embolisation, liver resection, pancreatectomy) [15]. In the present modern era of imaging techniques, the cadaver still stands as an important and reliable mode of anatomical study $[26,51]$. Hence, the aim of this cadaveric study was to analyse and report the vascular patterns of CT for the first time in a sample of Polish population according to the classification by Adachi [1].

\section{MATERIALS AND METHODS}

Dissection of the CT was performed in 50 formalin-fixed abdomen specimens in the Department of Anatomy, Jagiellonian University Medical College. The inclusion criteria were cadavers of Polish nationality subjects. The sex and age was not taken into account. Cadavers with previous upper abdominal surgery, abdominal trauma, disease process that distorted the arterial anatomy or signs of putrefaction were excluded. This study was reviewed and approved by the local Ethics Committee (no. 1072.6120.78.2019). Informed consent was not required. After dissection of the anterior abdominal wall, and entering the peritoneal cavity, the greater omentum of the stomach was dissected from the transverse colon, exposing the posterior wall of the stomach and opening the lesser sac. The pylorus was freed from adjacent connective tissue, and the omentum minus was opened along the minor curvature. Once the CHA, the LGA and the SA were identified, their course was followed to their site of origin. The presence of a "true tripod" or a "false tripod" was examined. CT variations, accessory vessels and site of origin were recorded and referred to Adachi's classification. Care was taken not to overlook a left hepatic artery. The LGA was exposed as well as the coronary vein. The pancreas was also dissected to expose the origin of the superior mesenteric artery (SMA). The vertebral level of the CT origin was determined by palpation in cephalic direction beginning from the fifth lumbar vertebral body. The structures of the $A A$, its branches and variations were photographed using a digital camera.

\section{RESULTS}

During routine dissection of abdomen we observed the following branching patterns of $\mathrm{CT}$. Coeliac trunk divided into CHA, LGA and SA in $82 \%$ of the cadavers $(41 / 50)$. This pattern corresponds to Adachi type I. Furthermore, two different trifurcation 


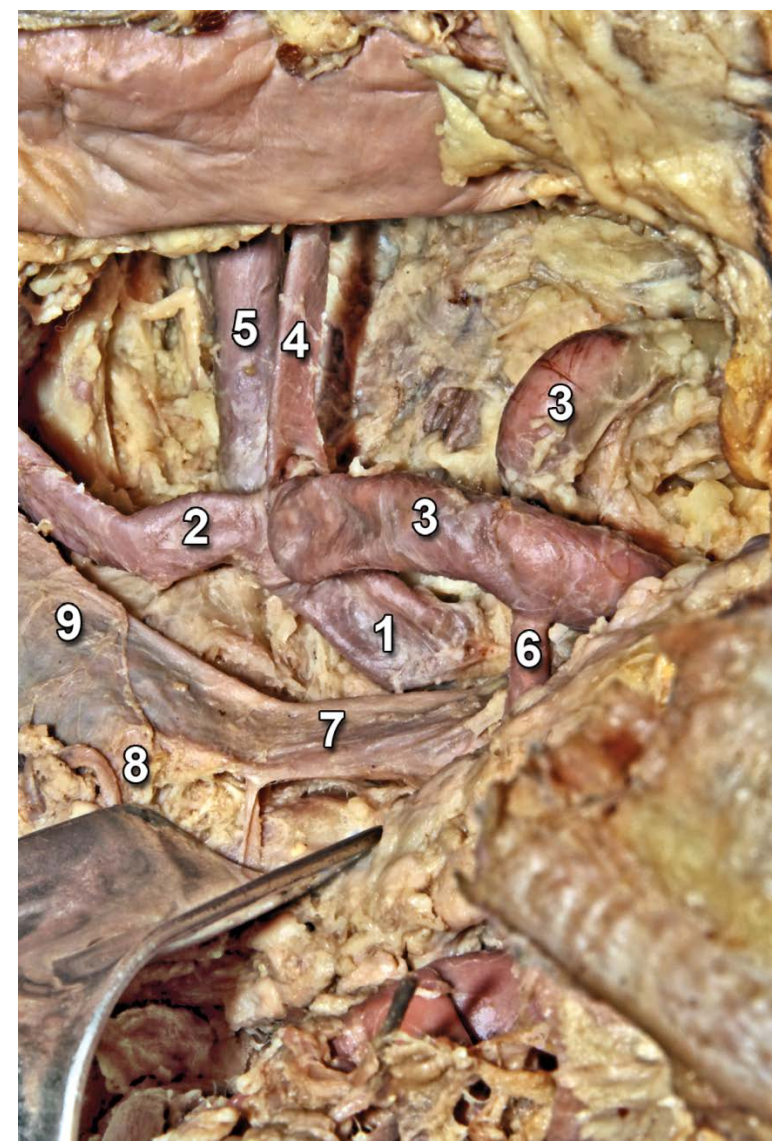

Figure 2. True tripod; 1 - coeliac trunk; $2-$ common hepatic artery; 3 - splenic artery; 4 - left gastric artery; 5 - left gastric vein; 6 - greater pancreatic artery; 7 - splenic vein; 8 - superior mesenteric vein; 9 - portal vein.

patterns were observed; a classical or "true" tripod called "tripus Halleri" and a non-classical type. In the classical type, CHA, SA and LGA were found to arise from the CT. This was found in $20 \%$ of dissections (8/41) (Figs. 2, 3). In the non-classical type also known as "false" tripod the origin of LGA was located relatively proximal, between the $A A$ and the bifurcation of $C T$, in 33 out of the 41 cadavers $(80 \%)$ (Figs. 4, 5). Bifurcation of the CT (Adachi type II) was found in $16 \%$ of the cadaveric dissections (8/50). The CT divided into CHA and SA (hepatosplenic trunk) whereas LGA originated directly from the AA (Fig. 6). In 1 case, an accessory left inferior phrenic artery (LIPA) was found, rising from the LGA. The given variability was observed in $2 \%$, which corresponds to $1 / 50$ of cadavers. In addition, our attention was drawn by false tripod with two additional arteries: namely the LIPA from LGA and the greater pancreatic artery from SA. Such a variation occurred in $2 \%(1 / 50$ of cadavers). The variations found in the present study in comparison to other cadaveric studies were

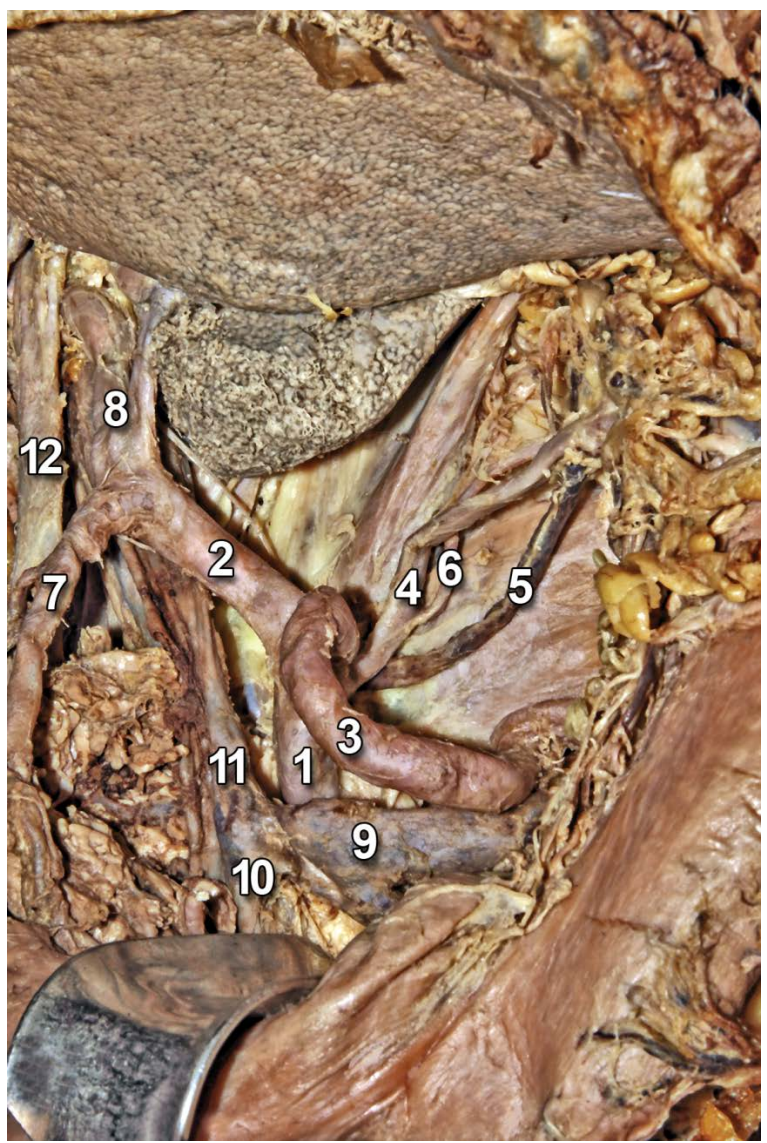

Figure 3. True tripod; $1-$ coeliac trunk; $2-$ common hepatic artery; 3 - splenic artery; 4 - left gastric artery; 5 — left gastric vein; 6 - right inferior phrenic artery; 7 - gastroduodenal artery; 8 - proper hepatic artery; 9 - splenic vein; 10 - superior mesenteric vein; 11 - portal vein; 12 - common bile duct.

summarised in Table 1. Considering the prevalence of using the computed tomography angiography (CTA) in analysing anatomical variations, we also compared our results with the radiological studies in Polish population (Table 2). Correlation between gender and CT variation is given in Table 3. The level of $C T$ origin was found to be at the inter-vertebral disc between $\mathrm{T} 12$ and $\mathrm{L} 1$ in all of the cases. Level of origin $\mathrm{CT}$ in different variations presented in Table 4.

\section{DISCUSSION}

Anatomic variations of $\mathrm{CT}$ has been described by many authors in various classifications i.e. Rossi and Cova (1904) [38], Lariche and Villemin (1907) [23], Descomps (1910) [9], Picquand (1910) [35], de Rio Branco (1912) [37], Lipschutz (1917) [24], Eaton (1917) [10], Adachi (1928) [1], Tsukamoto (1929) [45], Imakoshi (1949) [16], Michels (1955) [27], Kozhevnikova (1977) [21], Katsume et al. (1978) [18], Vandamme and Bonte (1985) [46], Nelson et 


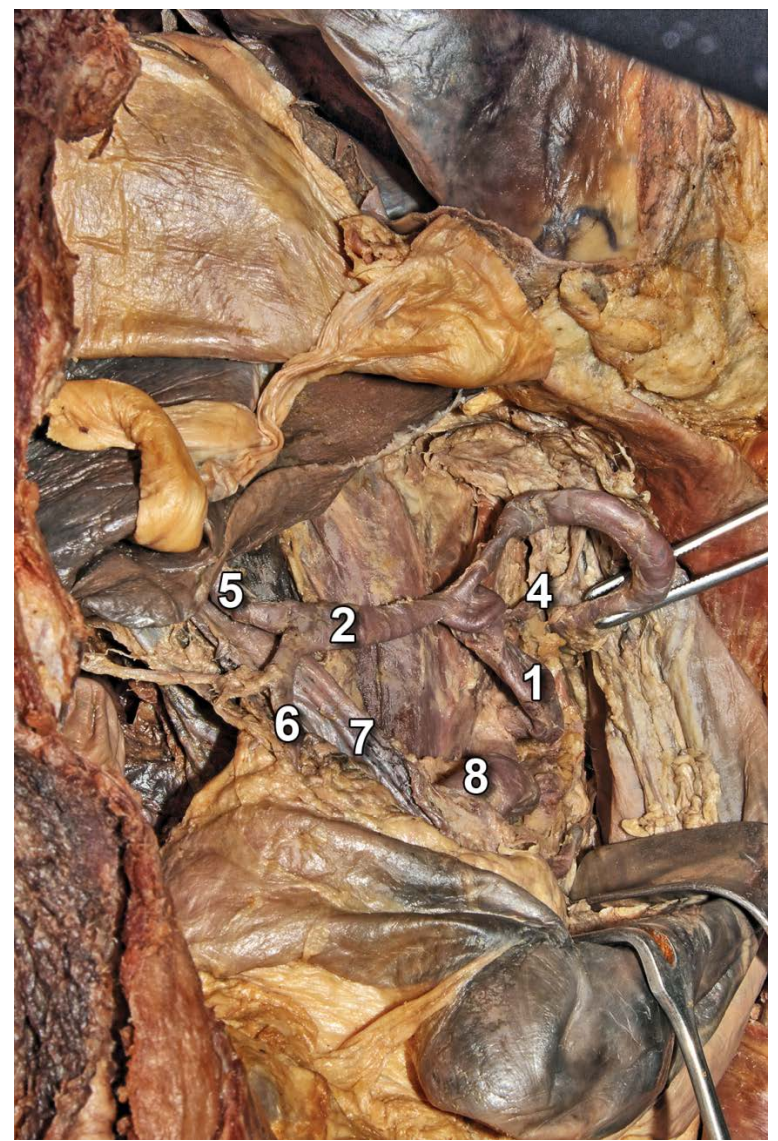

Figure 4. False tripod; $1-$ coeliac trunk; $2-$ common hepatic artery; 3 - splenic artery; 4 - left gastric artery; 5 - proper hepatic artery; 6 - gastroduodenal artery; 7 - portal vein; 8 superior mesenteric artery.

al. (1988) [30], Kaneko (1990) [17], Chen (2009) [7], Shoumura et al. (1991) [40], Wadhwa Ambica (2011) [48], Panagouli (2013) [32], Olewnik et al. (2017) [31]. In our study we referred to Adachi [1] and Michels [27] who have classified the CT into six different types. However, these classifications do not include all observed variants of the CT as well as accessory or replaced hepatic arteries, both of them are still being mentioned and compared with newly described ones $[8,12,26,32,34,41,44]$. Furthermore, Adachi's and Michel's classifications described in textbooks were recently considered to create a scheme of the most frequent variants of the $\mathrm{CT}$ and anatomy of the hepatic circulation [7, 41]. Michel's classification was also used for depiction of $\mathrm{CT}$ and CHA variations in children [5]. Favelier et al. [11] mentioned that this classification provides the best anatomical approach. The types of CT according to Michels' classification are as follows: type 1 -normal branching; type 2 - hepatosplenic trunk and LGA

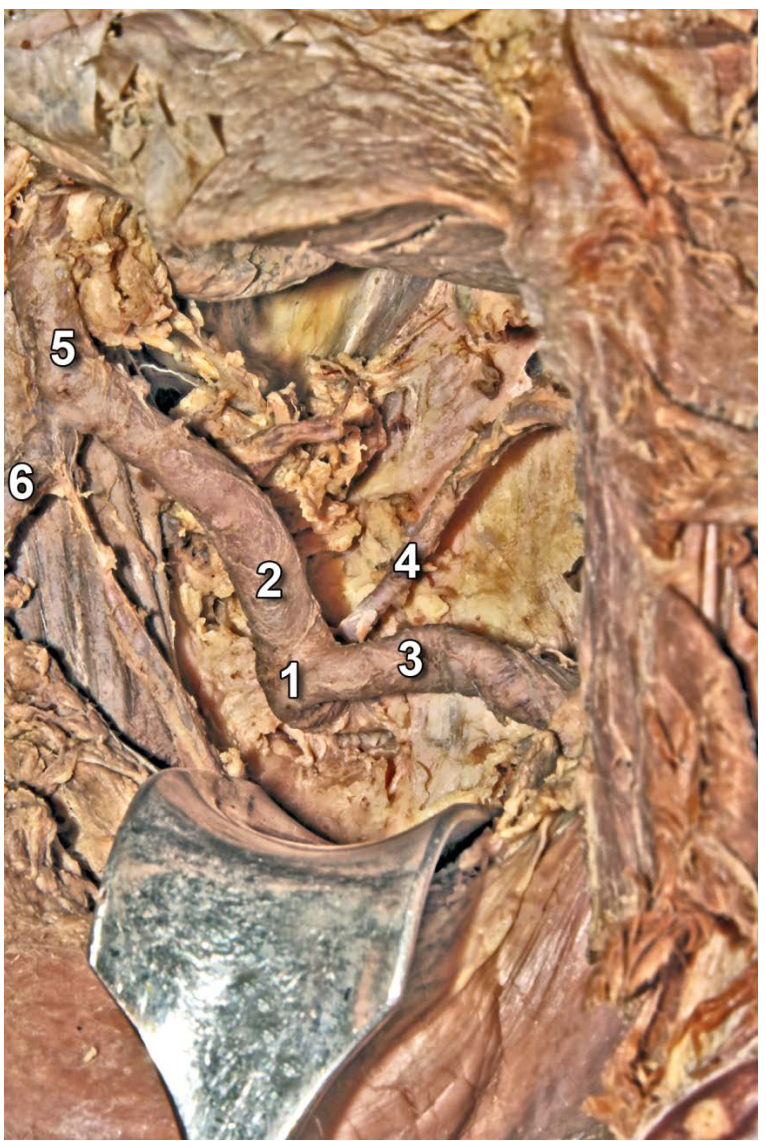

Figure 5. False tripod; 1 - coeliac trunk; $2-$ common hepatic artery; 3 - splenic artery; 4 - left gastric artery; 5 - proper hepatic artery; 6 - gastroduodenal artery.

from aorta; type 3 - hepatosplenomesenteric trunk and left gastric from aorta; type 4 - hepatogastric trunk and SA from SMA; type 5 - splenogastric type; splenic and left gastric from the $\mathrm{CT}$ and $\mathrm{CHA}$ from SMA; and type 6-coeliacomesenteric trunk; splenic, left gastric, common hepatic and superior mesenteric arteries arise from a common trunk [27, 40]. Indeed, the most prevalent is type 1 , which occurs in $86 \%$ of the population [13]. We observed this type in $83.33 \%$ of cadavers. Type 2 occurring in $8 \%$ of population, was found in our study in $16.67 \%$ of cases. We did not observe other less common types i.e. type 3 (hepatosplenovisceral trunk), type 4 (visceromesenteric trunk), type 5 (hepatomesenteric trunk), type 6 (gastrosplenic trunk). Absence of the $\mathrm{CT}$ is the most infrequent variation, with a mean prevalence of $0.38 \%$. In many studies, no CT absence has been found $[2,7,15,24]$. In our study, no case of absence of CT was found (Table 1). It is important to notice that Olewnik et al. [31] revealed a shedload of CT variations non-classified by Adachi (27\%) 


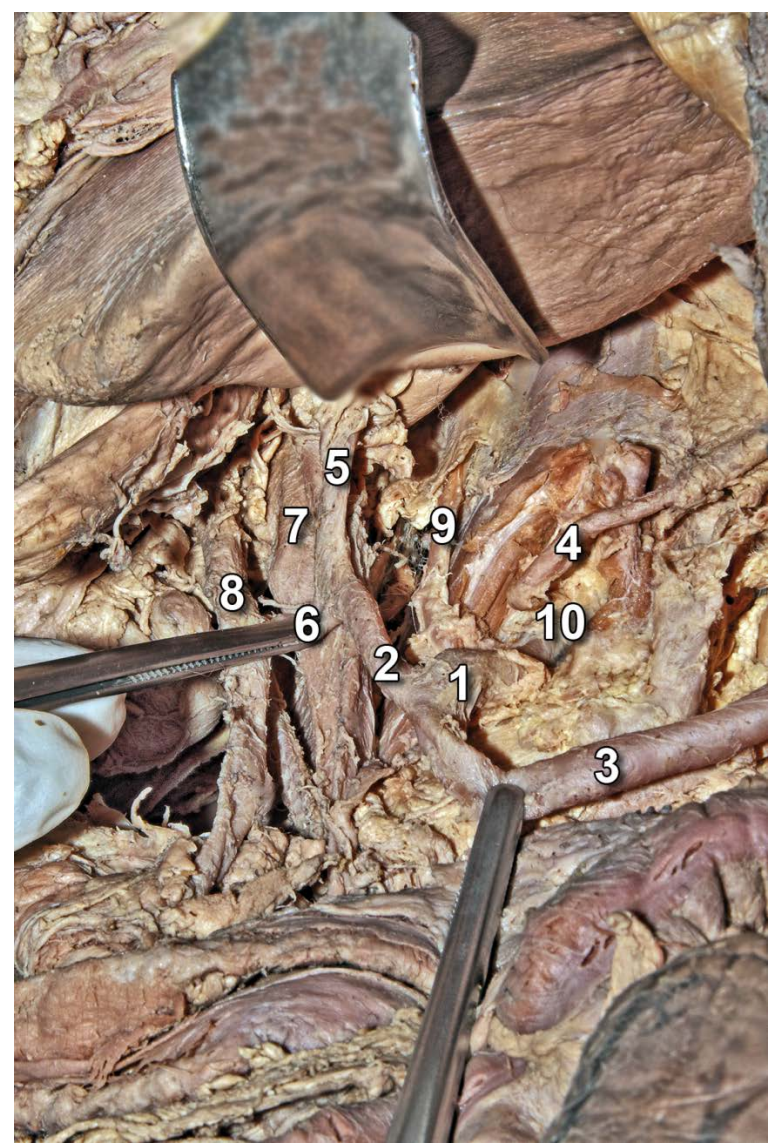

Figure 6. Hepatosplenic trunk + left gastric artery rising separately from abdominal aorta; 1 - coeliac trunk; 2 - common hepatic artery; 3 - splenic artery; 4 - left gastric artery; 5 - proper hepatic artery; 6 - gastroduodenal artery; 7 - portal vein; 8 common bile duct; 9 - right inferior phrenic artery; $10-$ abdominal aorta.

Table 1. Comparison between our study and the other cadaveric studies according to the Adachi's classification

\begin{tabular}{lccccccc}
\hline $\begin{array}{l}\text { Cadaveric } \\
\text { study }\end{array}$ & I & II & III & IV & V & VI & Other \\
\hline Our study & $82.0 \%$ & $16.0 \%$ & $0.0 \%$ & $0.0 \%$ & $0.0 \%$ & $0.0 \%$ & $2.0 \%$ \\
Lipshutz [24] & $73.5 \%$ & $13.3 \%$ & $0.0 \%$ & $2.4 \%$ & $0.0 \%$ & $3.6 \%$ & $7.2 \%$ \\
Adachi [1] & $87.7 \%$ & $6.4 \%$ & $1.2 \%$ & $2.4 \%$ & $0.4 \%$ & $2.0 \%$ & $0.0 \%$ \\
Chen et al. [7] & $89.8 \%$ & $4.3 \%$ & $0.7 \%$ & $0.7 \%$ & $1.5 \%$ & $1.8 \%$ & $1.0 \%$ \\
Marco-Clem- & $86.0 \%$ & $14.0 \%$ & $0.0 \%$ & $0.0 \%$ & $0.0 \%$ & $0.0 \%$ & $0.0 \%$ \\
ent et al. [26] & & & & & & & \\
Olewnik et al. & $62.5 \%$ & $10.0 \%$ & $0.0 \%$ & $0.0 \%$ & $0.0 \%$ & $0.0 \%$ & $27.5 \%$ \\
[31] & & & & & & & \\
\hline
\end{tabular}

such as: 1) quadrifurcation - normal trifurcation + accessory hepatic artery: $7.5 \%$; 2) coeliacophrenic trunk - normal trifurcation + LIPA: $12.5 \%$; 3) trifurcation - hepatosplenic artery + accessory hepatic artery: $5.0 \%$; 4) absence of the CT: $2.5 \%$ [31], so we compared our results with other cadaveric studies of the non-Polish populations (Table 1).

Kornafel et al. [20] studied the variations of the main branches of the AA including CT and SMA using CTA and 64-detector computed tomography scanner in 201 patients. The authors did not base on the Adachi's or Michels' classification and observed 95.5\% cases of the normal trifurcation. Other variations observed were hepatosplenic trunk (1.5\%), coeliacomesenteric trunk (1.5\%) and the gastrosplenic trunk (0.5\%) [20]. Torres et al. [44] also analysed variations of the $\mathrm{CT}$ using multidetector computed tomography according to the Uflacker's classification. In this study the most common trifurcation was observed in $1455 / 1569$ cases (92.7\%), the other variants were: gastrosplenic trunk in 64/1569 cases (4.1\%) and hepatosplenic trunk in 34 cases $(2.2 \%)$. Coeliac-mesenteric trunk (8/1569; 0.5\%), hepatogastric trunk (4/1569; $0.2 \%)$ were rarely observed. In 2 cases the absence of the CT was noted $(0.1 \%)$. The hepatosplenomesenteric trunk and the coeliaco-colic trunk were not detected [44] Kurcz et al. [22] presented results of the study on 240 patients. The most common patterns were: trifurcation (87.5\%), hepatosplenic trunk (8.33\%) and gastrosplenic trunk (3.33\%). In 1 case $\mathrm{CT}$ was absent $(0.42 \%)$ and hepatogastric trunk was observed in $0.42 \%$. We compared our results on cadavers with radiologic studies (Table 2 ).

Due to high number of articles describing variations of the CT, there was a necessity to find appropriate results evaluated in one review. Santos et al. [39] and Whitley et al. [50] presented results of the previous studies about the $\mathrm{CT}$ and their findings were used to elaborate and compare our results with the other studies focused on the Polish population or the cadaveric studies.

Anson et al. [2] showed in cadaveric studies that almost $75 \%$ of cases had CT origin at the level of inter-vertebral disc between T12 and L1. In our study, the site of origin was also found to be at the abovementioned level in most of the cases, which does not differ from the population norm.

The most common additional branches of the CT are single or double inferior phrenic arteries, which were described in $40 \%$ of cases in the study by Loukas et al. [25]. In our study, additional vessels were found in $2.77 \%$ of cadavers. In one autopsy specimen, the inferior phrenic artery arising from LGA and greater pancreatic artery arising from SA were found. In CTA scans Srivastava et al. [42] revealed visceral trifurca- 
Table 2. Comparison between our cadaveric study and radiological studies in Polish population

\begin{tabular}{lcccc}
\hline Type of variation & $\begin{array}{c}\text { Present study } \\
\mathbf{N = 5 0}\end{array}$ & $\begin{array}{c}\text { Kornafel et al. [20] } \\
\mathbf{N = 2 0 1}\end{array}$ & $\begin{array}{c}\text { Torres et al. [44] } \\
\mathbf{N}=\mathbf{1 5 6 9}\end{array}$ & $\begin{array}{c}\text { Kurcz et al. [22] } \\
\mathbf{N}=\mathbf{2 4 0}\end{array}$ \\
\hline Normal branching & $83.33 \%$ & $95.50 \%$ & $92.70 \%$ & $87.50 \%$ \\
Hepatosplenic trunk & $16.67 \%$ & $1.50 \%$ & $2.20 \%$ & $8.33 \%$ \\
Hepatosplenomesenteric trunk & $0.0 \%$ & $0.0 \%$ & $0.0 \%$ & $0.0 \%$ \\
Hepatogastric trunk & $0.0 \%$ & $0.0 \%$ & $0.20 \%$ & $0.42 \%$ \\
Gastrosplenic trunk & $0.0 \%$ & $0.50 \%$ & $4.10 \%$ & $3.33 \%$ \\
Coeliacomesenteric trunk & $0.0 \%$ & $1.50 \%$ & $0.50 \%$ & $0.0 \%$ \\
Absence of coeliac trunk & $0.0 \%$ & $0.0 \%$ & $0.10 \%$ & $0.42 \%$ \\
Other (for example coeliac-colic trunk) & $0.0 \%$ & $1.0 \%$ & $0.0 \%$ & $0.0 \%$ \\
\hline
\end{tabular}

$\mathrm{N}$ - number of patients

Table 3. Correlation between gender and variation of the coeliac trunk $(\mathrm{n}=50)$

\begin{tabular}{lcc}
\hline Type of variation & Male & Female \\
\hline Hepatogastrosplenic trunk & 28 & 13 \\
Hepatosplenic trunk & 7 & 2 \\
Hepatosplenomesenteric trunk & 0 & 0 \\
Coeliacomesenteric trunk & 0 & 0 \\
Hepatomesenteric trunk & 0 & 0 \\
Gastrosplenic trunk & 0 & 0 \\
\hline
\end{tabular}

tion in $28 \%$, bifurcation in $8 \%$, quadrifurcation in $36 \%$, pentafurcation in $20 \%$, hexafurcation in $4 \%$, while in $4 \%$ of cases visceral trunk was absent.

Anatomical variations of the $\mathrm{CT}$ are secondary to the embryonic developmental changes in the ventral segmental arteries [43]. Primitive segmental branches arise from the dorsal aorta and form the CT and the SMA. These branches are connected to the ventral longitudinal anastomotic channel. Retention or disappearance of parts of this primitive arterial plexus will give rise to variations of the CT and the SMA [14].

In studies carried out by Venieratos et al. [47] and Chen et al. [7] no differences were found between genders. However, the occurrence of different types of CT can be influenced by ethnicity [32]. Our study was carried out on the cadavers of Polish nationality presenting a trifurcated $\mathrm{CT}$, either a common origin or with one of the three arteries arising first. This incidence is higher than those observed in Korean (10.9\%), Caucasian (8.6\%), Japanese (10.7\%), Indian (30\%) and Afro-American population (39\%) [36].

Detailed knowledge of normal CT anatomy and its variations is very important during surgery such as pancreatoduodenectomy, liver transplant as well as
Table 4. Level of origin coeliac trunk in different variations ( $n=50$ )

\begin{tabular}{lcc}
\hline Type of variation & T12 (n) & L1 (n) \\
\hline Hepatogastrosplenic trunk & 27 & 14 \\
Hepatosplenic trunk & 3 & 6 \\
Hepatosplenomesenteric trunk & 0 & 0 \\
Coeliacomesenteric trunk & 0 & 0 \\
Hepatomesenteric trunk & 0 & 0 \\
Gastrosplenic trunk & 0 & 0 \\
\hline
\end{tabular}

hepatic artery infusion chemotherapy. Preoperative imaging can help better preparation and planning by the surgical team. However, all arterial variations may not be detected in preoperative imaging (only up to $60-80 \%$ of cases). If detected, it can help the surgeons to identify the artery and prevent its injury during surgery and post-operative complications like bleeding and ischaemia [14]. Currently, arterial variations can also be predicted by the intrauterine ultrasonography examination and observations of the foetus' intestine position in the following stages of the foetal development [51]. Another modified ultrasonography examination - the three-dimensional contrast-enhanced ultrasonography - could be used in precisely non-invasive diagnosing the coeliac artery compression syndrome [49]. The pathologies of CT and SMA also could be detected by using new technique of the non-contrast magnetic resonance angiography [39].

Hepatic artery variations, such as anomalous right hepatic artery crossing posterior to the portal vein, are frequently seen (13\%). These patients, when undergoing pancreatoduodenectomy, may require a change in the surgical approach to achieve an ad- 
equate resection. Preoperative imaging can clearly identify such variations and help to achieve a safer pancreatic head dissection with proper surgical planning [3]. In transarterial chemoembolisation (TACE) or radioembolisation of hepatic cancers and metastases it is essential to analyse hepatic and extrahepatic perfusion in order to prevent iatrogenic postprocedural complications such as radiation induced ulcers in the stomach and duodenum or severe pancreatitis $[4,6$, 33]. The variations of the $\mathrm{CT}$ are also significant during TACE in therapy of the pancreas cancer (especially the variations of the $\mathrm{CHA}$ ) [29]. Anatomical variations of the $\mathrm{CT}$ are also significant to know in planning the bariatric procedures such as LGA embolisation or the sleeve gastrectomy $[19,28]$.

\section{CONCLUSIONS}

Coeliac trunk variations are not uncommon findings, with different anatomic variants being reported. The classical visceral trifurcation was found in Polish population with a comparable frequency, as described by Adachi [1]. Only a low percentage of cases with additional vessels were found. Thus, the importance of knowing the possible variations of this structure is emphasized, which may have implications for surgical interventions and imaging studies related to the abdominal region.

\section{REFERENCES}

1. Adachi B. Das arteriensystem der Japaner, vol 2. Kenkyusha Press, Kyoto 1928: 18-71.

2. Anson B, McVay C. The topographical positions and the mutual relations of the visceral branches of the abdominal aorta. A study of 100 consecutive cadavers. Anat Rec. 1936; 67(1): 7-15, doi: 10.1002/ar.1090670103.

3. Balzan SM, Gava VG, Pedrotti S, et al. Prevalence of hepatic arterial variations with implications in pancreatoduodenectomy. Arq Bras Cir Dig. 2019; 32(3): e1455, doi: 10.1590/0102-672020190001e1455, indexed in Pubmed: 31644675.

4. Boas FE, Bodei L, Sofocleous CT. Radioembolization of colorectal liver metastases: indications, technique, and outcomes. J Nucl Med. 2017; 58(Suppl 2): 104S-111S, doi: 10.2967/jnumed.116.187229, indexed in Pubmed: 28864605.

5. Caliskan E, Acar T, Ozturk M, et al. Coeliac trunk and common hepatic artery variations in children: an analysis with computed tomography angiography. Folia Morphol. 2018; 77(4): 670-676, doi: 10.5603/FM.a2018.0037, indexed in Pubmed: 29651794.

6. Catalano $\mathrm{OA}$, Singh $\mathrm{AH}$, Uppot RN, et al. Vascular and biliary variants in the liver: implications for liver surgery. Radiographics. 2008; 28(2): 359-378, doi: 10.1148/ rg.282075099, indexed in Pubmed: 18349445.
7. Chen $H$, Yano R, Emura $S$, et al. Anatomic variation of the celiac trunk with special reference to hepatic artery patterns. Ann Anat. 2009; 191(4): 399-407, doi: 10.1016/j. aanat.2009.05.002, indexed in Pubmed: 19540742.

8. Cirocchi R, D'Andrea V, Lauro A, et al. The absence of the common hepatic artery and its implications for surgical practice: Results of a systematic review and meta-analysis. Surgeon. 2019; 17(3): 172-185, doi: 10.1016/j. surge.2019.03.001, indexed in Pubmed: 30948331.

9. Descomps P. Le Tronc coeliaque. G S Teinheil, Paris 1910.

10. Eaton P. The coeliac axis. Anat Rec. 1917; 13(6): 369-374, doi: 10.1002/ar.1090130605.

11. Favelier S, Germain T, Genson PY, et al. Anatomy of liver arteries for interventional radiology. Diagn Interv Imaging. 2015; 96(6): 537-546, doi: 10.1016/j.diii.2013.12.001, indexed in Pubmed: 24534562.

12. Fonseca-Neto OC, Lima HC, Rabelo P, et al. Anatomic variations of hepatic artery: a study in 479 liver transplantations. Arq Bras Cir Dig. 2017; 30(1): 35-37, doi: 10.1590/01026720201700010010, indexed in Pubmed: 28489166.

13. Haller VA. Icones anatomicae in quibus peaecipuae aliquae partes corporis humani delineatae proponuntur et arteriarum potissimum historia continetur. Vandenhoeck, Gottingen 1756: 27-36.

14. Hemamalini H. Variations in the branching pattern of the celiac trunk and its clinical significance. Anat Cell Biol. 2018; 51(3): 143-149, doi: 10.5115/acb.2018.51.3.143, indexed in Pubmed: 30310705.

15. Hiatt JR, Gabbay J, Busuttil RW. Surgical anatomy of the hepatic arteries in 1000 cases. Ann Surg. 1994; 220(1): 50-52, doi: 10.1097/00000658-199407000-00008, indexed in Pubmed: 8024358.

16. Imakoshi K. Study of the abdominal arterial supply. Vol. 37. Achievements of Department Anat. Kanazawa Med. Univ, 1949, pp. 1-14: as cited by Chen et al. 2009.

17. Kaneko $O$. The arterial distribution to the abdominal digestive organs in human fetuses. Kaibogaku Zasshi. 1990; 66: 452-461.

18. Katsume K, Kanamura E, Sakai K, et al. Statistics report concerning variations in abdominal visceral arterial supply. Kurume Igaku Zasshi. 1978; 41: 266-273.

19. Kordzadeh A, Lorenzi B, Hanif MA, et al. Left gastric artery embolisation for the treatment of obesity: a systematic review. Obes Surg. 2018; 28(6): 1797-1802, doi: 10.1007/ s11695-018-3211-2, indexed in Pubmed: 29616467.

20. Kornafel O, Baran B, Pawlikowska I, et al. Analysis of anatomical variations of the main arteries branching from the $a b-$ dominal aorta, with 64-detector computed tomography. Pol J Radiol. 2010; 75(2): 38-45, indexed in Pubmed: 22802775.

21. Kozhevnikova TI. Age and individual characteristics in the structure of the celiac trunk in man. Ark Anat Gistol Embriol. 1977; 72: 19-25.

22. Kurcz J, Nienartowicz E, Stonina J, et al. The usefulness of CT-angiography in detecting anatomical variants of arteries arising from the abdominal aorta and aortic arch. Adv Clin Exp Med. 2007; 16: 751-760.

23. Leriche, Villemin. Bibliogr. Anatom. Paris, 1907, as cited by Bergman et al. 2006.

24. Lipschutz B. A composite study of the cceliac axie artery. Ann Surg. 1917; 65(2): 159-169, doi: 10.1097/00000658191702000-00006. 
25. Loukas M, Hullett J, Wagner T. Clinical anatomy of the inferior phrenic artery. Clin Anat. 2005; 18(5): 357-365, doi: 10.1002/ca.20112, indexed in Pubmed: 15971218.

26. Marco-Clement I, Martinez-Barco A, Ahumada N, et al. Anatomical variations of the celiac trunk: cadaveric and radiological study. Surg Radiol Anat. 2016; 38(4): 501-510, doi: 10.1007/s00276-015-1542-4, indexed in Pubmed: 26267305.

27. Michels NA. Blood supply and anatomy of the upper abdominal organs with a descriptive atlas. Observations on the blood supply of the liver and gallbladder (200 dissections). Lippincott, Philadelphia 1955: 139-140.

28. Mui WLM, Lee DWH, Lam KKY. Laparoscopic sleeve gastrectomy with loop bipartition: A novel metabolic operation in treating obese type II diabetes mellitus. Int J Surg Case Rep. 2014; 5(2): 56-58, doi: 10.1016/j.ijscr.2013.12.002, indexed in Pubmed: 24441436.

29. Murata S, Onozawa S, Mine T, et al. Minimizing systemic leakage of cisplatin during percutaneous isolated pancreas perfusion chemotherapy: a pilot study. Radiology. 2015; 276(1): 102-109, doi: 10.1148/radiol.15141596, indexed in Pubmed: 25734552.

30. Nelson $\mathrm{T}$, Pollak $\mathrm{R}$, Jonasson $\mathrm{O}$, et al. Anatomic variants of the celiac, superior mesenteric, and inferior mesenteric arteries and their clinical relevance. Clin Anat. 1988; 1(2): 75-91, doi: 10.1002/ca.980010202.

31. Olewnik $\measuredangle$, Wysiadecki G, Polguj M, et al. Types of coeliac trunk branching including accessory hepatic arteries: a new point of view based on cadaveric study. Folia Morphol. 2017; 76(4): 660-667, doi: 10.5603/FM.a2017.0053, indexed in Pubmed: 28612916.

32. Panagouli $E$, Venieratos D, Lolis E, et al. Variations in the anatomy of the celiac trunk: A systematic review and clinical implications. Ann Anat. 2013; 195(6): 501-511, doi: 10.1016/j. aanat.2013.06.003, indexed in Pubmed: 23972701.

33. Paprottka PM, Jakobs TF, Reiser MF, et al. Practical vascular anatomy in the preparation of radioembolization. Cardiovasc Intervent Radiol. 2012; 35(3): 454-462, doi: 10.1007/ s00270-011-0169-z, indexed in Pubmed: 21567273.

34. Petrella S, Rodriguez C, Sgrott E, et al. Anatomy and variations of the celiac trunk. Int J Morphol. 2007; 25(2), doi: 10.4067/s0717-95022007000200002.

35. Picquand G. Researches surl'anatomie du trone coelia que et de ses branches. Bibliogr Anat. 1910; 19: 159-201.

36. Pinal-Garcia DF, Nuno-Guzman CM, Gonzalez-Gonzalez ME, et al. The celiac trunk and its anatomical variations: a cadaveric study. J Clin Med Res. 2018; 10(4): 321-329, doi: 10.14740/jocmr3356w, indexed in Pubmed: 29511421.

37. Rio Branco P. Essaisurl'anatomic et la medicine operatoire du trone coeliaque et de ses branches de l'artere hepatique en particulier. G Steinheil, Paris 1912: 828.

38. Rossi G, Cova E. Sudio morfologico delle arterie dello stomaco. Arch Ital di Anat e di Embryol. 1904; 3: 485-526.
39. Santos PV, Barbosa AB, Targino VA, et al. Anatomical variations of the celiac trunk: a systematic review. Arq Bras Cir Dig. 2018; 31(4): e1403, doi: 10.1590/0102672020180001e1403, indexed in Pubmed: 30539978.

40. Shoumura S, Emura S, Utsumi M. Anatomical study on the branches of the celiac trunk (IV). Comparison of the findings with Adachi's classification. Kaibogaku Zasshi. 1991; 66: 452-461.

41. Song SY, Chung JW, Yin YH, et al. Celiac axis and common hepatic artery variations in 5002 patients: systematic analysis with spiral CT and DSA. Radiology. 2010; 255(1): 278-288, doi: 10.1148/radiol.09090389, indexed in Pubmed: 20308464.

42. Srivastava AK, Sehgal G, Sharma PK, et al. Various types of branching patterns of celiac trunk. FASEB J. 2012; 26(Suppl 1): 772.5.

43. Tandler J. Uber die Varietäten der Arteria coeliaca und deren Entwickelung. Beiträge und Referate zur Anatomie und Entwickelungsgeschichte. 1904; 25(2): 473-500, doi: 10.1007/bf02300762.

44. Torres K, Staśkiewicz G, Denisow M, et al. Anatomical variations of the coeliac trunk in the homogeneous Polish population. Folia Morphol. 2015; 74(1): 93-99, doi: 10.5603/FM.2014.0059, indexed in Pubmed: 25792402.

45. Tsukamoto $\mathrm{N}$. The branches of the abdominal visceral arteries in Japanese. Kaibogaku Zasshi 2. 1929: 780-829, as cited by Chen et al. 2009.

46. Vandamme JP, Bonte J. The branches of the celiac trunk. Acta Anat (Basel). 1985; 122(2): 110-114, doi: 10.1159/000145991, indexed in Pubmed: 4013640.

47. Venieratos D, Panagouli E, Lolis E, et al. A morphometric study of the celiac trunk and review of the literature. Clin Anat. 2013; 26(6): 741-750, doi: 10.1002/ca.22136, indexed in Pubmed: 22886953.

48. Wadhwa Ambica. A composite study of coeliac trunk in 30 adult human cadavers - its clinical implications. Global J Med Res. 2011; 11(1): 35-38.

49. Wang XM, Hua XP, Zheng GL. Celiac artery compression syndrome evaluated with 3-D contrast-enhanced ultrasonography: a new approach. Ultrasound Med Biol. 2018; 44(1): 243-250, doi: 10.1016/j.ultrasmedbio.2017.09.008, indexed in Pubmed: 29079396.

50. Whitley A, Oliverius $M$, Kocián $P$, et al. Variations of the celiac trunk investigated by multidetector computed tomography: Systematic review and meta-analysis with clinical correlations. Clin Anat. 2020; 33(8): 1249-1262, doi: 10.1002/ca.23576, indexed in Pubmed: 32012339.

51. Wozniak S, Florjanski J, Kordecki H, et al. Fetal sigmoid colon mesentery - In relevance in fetal ultrasound application. A pilot study. Ann Anat. 2018; 216: 152-158, doi: 10.1016/j.aanat.2017.12.003, indexed in Pubmed: 29292173. 